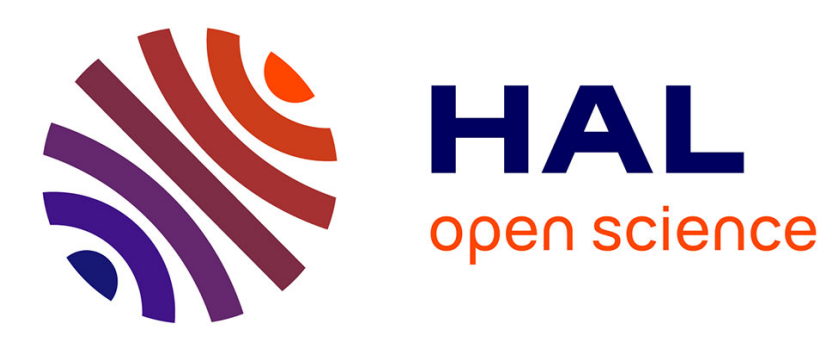

\title{
Systematic multimodeling methodology applied to an activated sludge reactor model
}

Anca Maria Nagy, Gilles Mourot, Benoît Marx, José Ragot, Georges Schutz

\section{To cite this version:}

Anca Maria Nagy, Gilles Mourot, Benoît Marx, José Ragot, Georges Schutz. Systematic multimodeling methodology applied to an activated sludge reactor model. Industrial and engineering chemistry research, 2010, 49 (6), pp.2790-2799. 10.1021/ie8017687 . hal-00978069

\section{HAL Id: hal-00978069 https://hal.science/hal-00978069}

Submitted on 12 Apr 2014

HAL is a multi-disciplinary open access archive for the deposit and dissemination of scientific research documents, whether they are published or not. The documents may come from teaching and research institutions in France or abroad, or from public or private research centers.
L'archive ouverte pluridisciplinaire HAL, est destinée au dépôt et à la diffusion de documents scientifiques de niveau recherche, publiés ou non, émanant des établissements d'enseignement et de recherche français ou étrangers, des laboratoires publics ou privés. 


\title{
Systematic Multimodeling Methodology Applied to an Activated Sludge Reactor Model
}

\author{
Anca Maria Nagy, ${ }^{* \dagger}$ Gilles Mourot, ${ }^{* \dagger}$ Benoît Marx, ${ }^{*}, \dagger$ José Ragot, ${ }^{*, \dagger}$ and Georges Schutz ${ }^{*, *}$ \\ Centre de Recherche en Automatique de Nancy, Nancy Université, 2, Avenue de la Forêt de Haye, \\ 54516 Vandoeuvre-lès-Nancy Cedex France, and Centre de Recherche Public "Henri Tudor", Laboratoire de \\ Technologies Industrielles et Matériaux, 29, Avenue John F. Kennedy, L-1855 Luxembourg-Kirchberg
}

In this article, an analytical method is used to obtain multiple model (MM) forms strictly equivalent to a given nonlinear model. The proposed method induces no information loss, contrary to existing order reduction methods. Several MMs formally equivalent to the initial model may be obtained, due to the intermediate quasi-LPV forms. Thus some criteria are given, using the linear matrix inequality (LMI) formulation, in order to chose the most suitable MM for analysis or control purpose. This method is applied to an activated sludge reactor model.

\section{Introduction}

The complexity problem of nonlinear dynamic systems appears in a great number of scientific and engineering fields. Numerous decomposition and simplification techniques were developed in the past years, in order to realize complexity reduction, according to objectives like identification, control, and stability analysis.

In most studies, the complexity reduction of nonlinear systems, represented in the state equation form, consists in the reduction of the system order that generally comes with an information loss. This order reduction is realized in different ways: parameter reduction of mathematical model from a sensitivity analysis and a comparison with the initial system, ${ }^{1,2}$ neglecting certain phenomena (reactions and/or species in the case of complex chemical mechanisms) whose explanatory power is weak in the initial system; ${ }^{3}$ elimination of model parts (parameters and/or variables) which have no significant importance on system dynamics; ${ }^{4,5}$ simplification by truncation and singular perturbation approximation. ${ }^{6,7}$

Another way to deal with complex systems is to use analytic transformations to obtain particular representations that are easier to study than a generic nonlinear form, in the sense that performance analysis, controller design, or supervision based on these new system representations is facilitated. In this paper, nonlinear systems are proved to be strictly equivalent to multiple models.

The multiple model ${ }^{8}$ actually constitutes a commonly used tool for dynamic nonlinear system modeling. The multiple model formalism is based on a nonlinear interpolation between certain linear submodels. The global model is a convex combination of the $r$ submodels: ${ }^{9}$

$$
\left\{\begin{array}{l}
\dot{x}(t)=\sum_{i=1}^{r} \mu_{i}(x, u)\left[A_{i} x(t)+B_{i} u(t)\right] \\
y(t)=\sum_{i=1}^{r} \mu_{i}(x, u)\left[C_{i} x(t)+D_{i} u(t)\right]
\end{array}\right.
$$

where $x \in \mathbb{R}^{n}$ represents the state vector, $u \in \mathbb{R}^{m}$ the input vector, and $y \in \mathbb{R}^{l}$ the output vector. $A_{i}, B_{i}, C_{i}, D_{i}$, are constant matrices of

* To whom correspondence should be addressed. E-mail: anca-maria.nagy@ensem.inpl-nancy.fr; gilles.mourot@ensem.inplnancy.fr; benoit.marx@ensem.inpl-nancy.fr; jose.ragot@ensem. inpl-nancy.fr; georges.schutz@tudor.lu.

Centre de Recherche en Automatique de Nancy.

CRP "Henri Tudor". appropriate dimensions, and $r$ denotes the number of submodels. The function $\mu_{i}(x, u)$ quantifies the relative weight of the $i$ th submodel $\left\{A_{i}, B_{i}, C_{i}, D_{i}\right\}$ in the global model. The weighting functions $\mu_{i}(x, u)$ are generated by the so-called premise variables, expressing different nonlinearities of the system, and they have the following property:

$$
\begin{gathered}
\sum_{i=1}^{r} \mu_{i}(x, u)=1 \\
\mu_{i}(x, u) \geq 0, \quad \forall(x, u) \in \mathbb{R}^{n} \times \mathbb{R}^{n}
\end{gathered}
$$

In the literature several equivalent terminologies are used to define this class of models: the multiple model (MM), ${ }^{8}$ the fuzzy Takagi-Sugeno model, ${ }^{10}$ the polytopic linear model (PLM). ${ }^{11}$

Different techniques exists to obtain a MM. The first technique is based on the linearization of the nonlinear model around one (or several) operating point(s). Dynamic linearization near an arbitrary trajectory is proposed as well. ${ }^{12}$ The second method consists in a system identification using experimental data. ${ }^{9,13}$ The loss of information constitutes the first drawback of these techniques. Second, the choice of the premise variables is not systematically realized. Third, the choice of different operating points or trajectories still remains very delicate.

In the present paper, the multiple model structure is used to reduce the complexity of an ASM1 model (activate sludge model 1$)^{17}$ describing a biological degradation process of an activated sludge reactor. Most of the previous works devoted to the activated sludge systems were based on linearization techniques, ${ }^{7,18}$ despite the drawbacks mentioned above.

Afterward, we will present a systematic procedure to transform a nonlinear system by rewriting it into a multiple model form, avoiding the major inconveniences: the transformation is realized without loss of information, the obtained system has exactly the same state trajectory as the initial system. Moreover, the choice of different operating points is no longer necessary. Starting with a general form of nonlinear system, a quasi-linear parameter varying (quasi-LPV) state representation is realized. In general, several equivalent quasi-LPV forms can be constructed from a given nonlinear dynamic model. Each quasiLPV form is associated to a particular premise variable set: choosing a quasi-LPV form is equivalent to choosing the premise variable set. This quasi-LPV representation constitutes a polytopic form because the matrices with variable parameters 
are convex combinations of constant matrices calculated from the polytope vertices. These vertices are obtained by using the convex polytopic transformation (CPT) ${ }^{19}$ Each vertex defines a linear submodel and the nonlinear parts are rejected into the weighting functions.

Most of the work done on the quasi-LPV systems in the framework of stability analysis or controller/observer design is only based on the matrices defining the vertices. As a consequence, even if the different quasi-LPV forms of a nonlinear system are formally equivalent, the obtained multiple model strongly depends on the chosen realization. The choice of the premise variable set is important, because it has an influence on the submodel number and on the global model structure. This degree of freedom will be used to ease the controllability, observability, stability analysis studies. So, it is possible to choose from different MM structures the one that ensures, for example, the convergence of the certain multiobserver forms which are based on the MM structure, with respect to given conditions. The convergence conditions of the state estimation error can be expressed in linear matrix inequality (LMI) formulation using the Lyapunov method ${ }^{21}$ and they are at the root of the MM choice rules making-out.

The proposed method generalizes the sector nonlinearity approach frequently used when dealing with Takagi-Sugeno models. ${ }^{16,20}$ The contribution of this paper is to give a systematic procedure in order to choose the best quasi-LPV form of a given nonlinear system with regard to the study objective (such as stability or performance analysis, controller or observer design).

In the first section, the general methodology to transform a nonlinear system into a multiple model form will be presented. The notion of convex polytopic transformation will be introduced and, using an example, some characteristics of this method will be underscored. The general case of this method will be presented in subsection Analytical Method of Structure Simplification. In subsection "Choice Criteria for Quasi-LPV Form", we will detail the choice between different quasi-LPV forms of a nonlinear system.

Before closing the paper with some conclusions, the proposed method is applied to an activated sludge model.

\section{Analytical Method of Structure Simplification of Nonlinear Systems}

This section is dedicated to the general methodology of transforming a given nonlinear model into a multiple model, eq 1. The proposed method is analytical, and the obtained multiple model is equivalent to the initial nonlinear system.

Considering a nonlinear system with bounded nonlinearities, a quasi-LPV form can be written from it. This form is a state and control affine representation. In general, for a nonlinear dynamic system, this representation is not unique, that is the reason why different criteria of choice for a quasi-LPV form have to be found according to the study objectives. To each quasi-LPV form, a premise variable set corresponds. These premise variables will be partitioned into two parts, using the convex polytopic transformation. The two partitions will contribute to the construction of multiple model submodels and to the corresponding weighting functions. The multiple model will be a convex combination of linear submodels, the nonlinearity being transferred into weighting functions related to each submodel.

Let us first introduce the notion of convex polytopic transformation that will serve afterward in the simplification methodology.
Convex Polytopic Transformation. Lemma 1. Let $h(x(t), u(t))$ be a bounded and continuous function from $\left[x_{0}, x_{1}\right] \times\left[u_{0}, u_{1}\right]$ to $\mathbb{R}$, with $x_{0}, x_{1} \in \mathbb{R}^{n}, u_{0}, u_{1} \in \mathbb{R}^{m}$. Then there exist two functions ${ }^{16}$

$$
\begin{gathered}
F_{i}:\left[x_{0}, x_{1}\right] \times\left[u_{0}, u_{1}\right] \longmapsto[0,1](i=1,2) \\
(x(t), u(t)) \longmapsto F_{i}(x(t), u(t))
\end{gathered}
$$

with $\mathrm{F}_{1}(x(t), u(t))+F_{2}(x(t), u(t))=1$ such that

$$
h(x(t), u(t))=F_{1}(x(t), u(t)) \cdot h_{1}+F_{2}(x(t), u(t)) \cdot h_{2}
$$

for all $h_{1} \geq \max _{x, u}\{h(x, u)\}$ and $h_{2} \geq \min _{x, u}\{h(x, u)\}$. The two functions $F_{1}$ and $F_{2}$ are defined by

$$
\begin{aligned}
& F_{1}(x(t), u(t))=\frac{h(x(t), u(t))-h_{2}}{h_{1}-h_{2}} \\
& F_{2}(x(t), u(t))=\frac{h_{1}-h(x(t), u(t))}{h_{1}-h_{2}}
\end{aligned}
$$

Let us note that this decomposition is not unique.

We can notice that the bigger $h_{1}$ is and the smaller $h_{2}$ is, the more the taken values of $F_{1}$ and $F_{2}$ are restricted in $[0,1]$ interval.

In particular, we can choose

$$
\begin{aligned}
& h_{1}=\max _{x, u}\{h(x, u)\} \\
& h_{2}=\min _{x, u}\{h(x, u)\}
\end{aligned}
$$

After the introduction of polytopic transformation, an example will be used in the following section to illustrate the proposed methodology to obtain a multiple model.

Introductory Example. Let us consider the following nonlinear system:

$$
\begin{gathered}
\dot{x}_{1}=\cos \left(x_{1}\right) x_{2}+x_{1}^{3} u \\
\dot{x}_{2}=\frac{1}{\sqrt{x_{2}}} x_{1}+x_{1}{ }^{2} x_{2}
\end{gathered}
$$

First, the system (3) can be represented in a quasi-LPV form:

$$
\dot{x}=A(x, u) x+B(x, u) u
$$

By realizing this transformation several quasi-LPV forms can be obtained, because this form is a state- and control-affine representation. For the first state eq $3 \mathrm{a}$, this separation is clear because of the product between the function $\cos \left(x_{1}\right)$ and the second state variable $x_{2}$. For the second term, $x_{1}^{3} u$, we can either affect the nonlinearity $x_{1}{ }^{3}$ in the control matrix $B$ eq 4 , or distribute this nonlinearity among the state vector $\left(x_{1}\right.$ component) and the state matrix $A$ eq 5 :

$$
\begin{array}{ll}
A(x)=\left[\begin{array}{ll}
0 & \cos \left(x_{1}\right) \\
\frac{1}{\sqrt{x_{2}}} & x_{1}{ }^{2}
\end{array}\right] & B(x)=\left[\begin{array}{l}
x_{1}^{3} \\
0
\end{array}\right] \\
A(x, u)=\left[\begin{array}{ll}
x_{1}{ }^{2} u & \cos \left(x_{1}\right) \\
\frac{1}{\sqrt{x_{2}}} & x_{1}{ }^{2}
\end{array}\right] & B(x)=\left[\begin{array}{l}
0 \\
0
\end{array}\right]
\end{array}
$$

For the second state eq $3 b$, at least two possible decompositions are observed. The most obvious decomposition is obtained by factorizing the two terms by $x_{1}$ and $x_{2}$, respectively, eq 4 . 
Another possibility is to factorize the right-hand terms of eq $3 \mathrm{~b}$ only by $x_{1}$, reducing in this way the number of premise variables to three, eq 6 .

$$
A(x)=\left[\begin{array}{ll}
0 & \cos \left(x_{1}\right) \\
\frac{1}{\sqrt{x_{2}}}+x_{1} x_{2} & 0
\end{array}\right] \quad B(x)=\left[\begin{array}{l}
x_{1}^{3} \\
0
\end{array}\right]
$$

In the following we only focus on the derivation of the MM form. The choice criteria between the possible forms of eq 4 , eq 5 and eq 6 will be discussed later.

Retaining for example the representation eq 6, the premise variable set $V_{z}=\left\{z_{1}, z_{2}, z_{3}\right\}$ is defined as follows:

$$
\begin{aligned}
& z_{1}(x)=\cos \left(x_{1}\right) \\
& z_{2}(x)=x_{1}^{3} \\
& z_{3}(x)=\frac{1}{\sqrt{x_{2}}}+x_{1} x_{2}
\end{aligned}
$$

The choice of these variables $z_{1}, z_{2}, z_{3}$ is directly linked to the chosen quasi-LPV form.

Second, the convex polytopic transformation is applied, for each premise variable $z_{j}(x)(j=1, \ldots, 3)$ for $x_{1} \in[-2 \pi, 2 \pi]$ and $x_{2} \in[0.1,12]$. Then, using lemma 1 , each premise variable will be partitioned into two parts:

$$
\begin{aligned}
& z_{1}(x)=F_{1,1}\left(z_{1}\right) z_{1,1}+F_{1,2}\left(z_{1}\right) z_{1,2} \\
& z_{2}(x)=F_{2,1}\left(z_{2}\right) z_{2,1}+F_{2,2}\left(z_{2}\right) z_{2,2} \\
& z_{3}(x)=F_{3,1}\left(z_{3}\right) z_{3,1}+F_{3,2}\left(z_{3}\right) z_{3,2}
\end{aligned}
$$

where

$$
\begin{aligned}
& F_{1,1}\left(z_{1}(x)\right)=\frac{\cos \left(x_{1}\right)-z_{1,2}}{z_{1,1}-z_{1,2}} \\
& F_{1,2}\left(z_{1}(x)\right)=\frac{z_{1,1}-\cos \left(x_{1}\right)}{z_{1,1}-z_{1,2}} \\
& F_{2,1}\left(z_{2}(x)\right)=\frac{x_{1}{ }^{3}-z_{2,2}}{z_{2,1}-z_{2,2}} \\
& F_{2,2}\left(z_{2}(x)\right)=\frac{z_{2,1}-x_{1}^{3}}{z_{2,1}-z_{2,2}} \\
& F_{3,1}\left(z_{3}(x)\right)=\frac{\frac{1}{\sqrt{x_{2}}}+x_{1} x_{2}-z_{3,2}}{z_{3,1}-z_{3,2}} \\
& F_{3,2}\left(z_{3}(x)\right)=\frac{z_{3,1}-\frac{1}{\sqrt{x_{2}}}-x_{1} x_{2}}{z_{3,1}-z_{3,2}}
\end{aligned}
$$

We choose here:

$$
\begin{aligned}
& z_{j, 1}=\max _{x}\left\{z_{j}(x)\right\} \\
& z_{j, 2}=\min _{x}\left\{z_{j}(x)\right\}
\end{aligned} \quad \forall j=1, \ldots, 3
$$

The functions $F_{j, 1}$ and $F_{j, 2}$ represent, respectively, the first and the second partition of each premise variable. Let us note that $A(x)$ contains as premise variables $z_{1}$ and $z_{3}$, while $B(x)$ contains as premise variable $z_{2}$; in this way, we will evaluate the matrices $A$ and $B$ at the vertices of the polytope defined by the partitions of the premise variables which occur in these matrices, as follows:
First, using the convex polytopic transformation (lemma 1) applied for $z_{1}$, eq 8a:

$$
A\left(z_{1}, z_{3}\right)=\left[\begin{array}{ll}
0 & z_{1}(x) \\
z_{3}(x) & 0
\end{array}\right]=F_{1,1}(x)\left[\begin{array}{ll}
0 & z_{1,1} \\
z_{3}(x) & 0
\end{array}\right]+F_{1,2}(x)\left[\begin{array}{ll}
0 & z_{1,2} \\
z_{3}(x) & 0
\end{array}\right]
$$

Then, using the convex polytopic transformation (lemma 1) applied for $z_{3} 8 \mathrm{c}$ :

$$
\begin{array}{r}
A\left(z_{1}, z_{3}\right)=F_{1,1}(x) F_{3,1}(x)\left[\begin{array}{ll}
0 & z_{1,1} \\
z_{3,1} & 0
\end{array}\right]+F_{1,2}(x) F_{3,1}(x)\left[\begin{array}{ll}
0 & z_{1,2} \\
z_{3,1} & 0
\end{array}\right]+ \\
F_{1,1}(x) F_{3,2}(x)\left[\begin{array}{ll}
0 & z_{1,1} \\
z_{3,2} & 0
\end{array}\right]+F_{1,2}(x) F_{3,2}(x)\left[\begin{array}{ll}
0 & z_{1,1} \\
z_{3,2} & 0
\end{array}\right]
\end{array}
$$

In order to also include the partitions of the second premise variable $z_{2}$, which is not involved in the matrix $A\left(z_{1}, z_{3}\right)$, but in $B\left(z_{2}\right)$, a multiplication with $F_{2,1}(x)+F_{2,2}(x)=1$ is realized as follows:

$$
\begin{aligned}
A\left(z_{1}, z_{3}\right) & =F_{1,1}(x) F_{2,1}(x) F_{3,1}(x)\left[\begin{array}{ll}
0 & z_{1,1} \\
z_{3,1} & 0
\end{array}\right]+F_{1,2}(x) F_{2,1}(x) F_{3,1}(x)\left[\begin{array}{ll}
0 & z_{1,2} \\
z_{3,1} & 0
\end{array}\right] \\
& +F_{1,1}(x) F_{2,2}(x) F_{3,1}(x)\left[\begin{array}{ll}
0 & z_{1,1} \\
z_{3,1} & 0
\end{array}\right]+F_{1,2}(x) F_{2,2}(x) F_{3,1}(x)\left[\begin{array}{ll}
0 & z_{1,2} \\
z_{3,1} & 0
\end{array}\right] \\
& +F_{1,1}(x) F_{2,1}(x) F_{3,2}(x)\left[\begin{array}{ll}
0 & z_{1,1} \\
z_{3,2} & 0
\end{array}\right]+F_{1,2}(x) F_{2,1}(x) F_{3,2}(x)\left[\begin{array}{ll}
0 & z_{1,2} \\
z_{3,2} & 0
\end{array}\right] \\
& +F_{1,1}(x) F_{2,2}(x) F_{3,2}(x)\left[\begin{array}{ll}
0 & z_{1,1} \\
z_{3,2} & 0
\end{array}\right]+F_{1,2}(x) F_{2,2}(x) F_{3,2}(x)\left[\begin{array}{ll}
0 & z_{1,2} \\
z_{3,2} & 0
\end{array}\right]
\end{aligned}
$$

The same transformations are performed on the matrix $B$, where the premise variable $z_{2}$ is involved:

$$
\begin{aligned}
& B\left(z_{2}\right)=\left[\begin{array}{l}
z_{2}(x) \\
0
\end{array}\right]=\left[\begin{array}{l}
z_{2,1} F_{2,1}(x)+z_{2,2} F_{2,2}(x) \\
0
\end{array}\right]=F_{2,1}(x)\left[\begin{array}{l}
z_{2,1} \\
0
\end{array}\right]+F_{2,2}(x)\left[\begin{array}{l}
z_{2,2} \\
0
\end{array}\right] \\
& =\left[F_{1,1}(x)+F_{1,2}(x)\right]\left[F_{3,1}(x)+F_{3,2}(x)\right]\left\{F_{2,1}(x)\left[\begin{array}{l}
z_{2,1} \\
0
\end{array}\right]+F_{2,2}(x)\left[\begin{array}{l}
z_{2,2} \\
0
\end{array}\right]\right\} \\
& B\left(z_{2}\right)=F_{1,1}(x) F_{2,1}(x) F_{3,1}(x)\left[\begin{array}{l}
z_{2,1} \\
0
\end{array}\right]+F_{1,2}(x) F_{2,1}(x) F_{3,1}(x)\left[\begin{array}{l}
z_{2,1} \\
0
\end{array}\right] \\
& +F_{1,1}(x) F_{2,2}(x) F_{3,1}(x)\left[\begin{array}{l}
z_{2,2} \\
0
\end{array}\right]+F_{1,2}(x) F_{2,2}(x) F_{3,1}(x)\left[\begin{array}{l}
z_{2,2} \\
0
\end{array}\right] \\
& +F_{1,1}(x) F_{2,1}(x) F_{3,2}(x)\left[\begin{array}{l}
z_{2,1} \\
0
\end{array}\right]+F_{1,2}(x) F_{2,1}(x) F_{3,2}(x)\left[\begin{array}{l}
z_{2,1} \\
0
\end{array}\right] \\
& +F_{1,1}(x) F_{2,2}(x) F_{3,2}(x)\left[\begin{array}{l}
z_{2,2} \\
0
\end{array}\right]+F_{1,2}(x) F_{2,2}(x) F_{3,2}(x)\left[\begin{array}{l}
z_{2,2} \\
0
\end{array}\right]
\end{aligned}
$$

Finally, looking at eq 10 and eq 11 we have

$$
A\left(z_{1}, z_{3}\right)=\sum_{i=1}^{8} \mu_{i}(x) A_{i}, \quad B\left(z_{2}\right)=\sum_{i=1}^{8} \mu_{i}(x) B_{i}
$$

where $\mu_{i}(x)$ are combination of $F_{j, k}(x)(j=1,2,3$ and $k=1,2)$ and where

$$
\begin{aligned}
A_{1}=A_{3} & =\left[\begin{array}{ll}
0 & z_{1,1} \\
z_{3,1} & 0
\end{array}\right] \quad A_{2}=A_{4}=\left[\begin{array}{ll}
0 & z_{1,1} \\
z_{3,2} & 0
\end{array}\right] \\
A_{5}=A_{7} & =\left[\begin{array}{ll}
0 & z_{1,2} \\
z_{3,1} & 0
\end{array}\right] \quad A_{6}=A_{8}=\left[\begin{array}{ll}
0 & z_{1,2} \\
z_{3,2} & 0
\end{array}\right] \\
B_{1}=B_{2} & =B_{5}=B_{6}=\left[\begin{array}{l}
z_{2,1} \\
0
\end{array}\right] B_{3}=B_{4}=B_{7}=B_{8}=\left[\begin{array}{l}
z_{2,2} \\
0
\end{array}\right]
\end{aligned}
$$


Table 1. Decomposition Table for Amultiplemodel with Three Premise Variables and Two Partitions for Each Variable

\begin{tabular}{ccccc}
\hline submodel $i$ & $\sigma_{i}$ & $A_{i}$ & $B_{i}$ & $\mu_{i}(x)$ \\
\hline 1 & $(1,1,1)$ & $A\left(z_{1,1}, z_{2,1}, z_{3,1}\right)$ & $B\left(z_{1,1}, z_{2,1}, z_{3,1}\right)$ & $F_{1,1}(x) F_{2,1}(x) F_{3,1}(x)$ \\
2 & $(1,1,2)$ & $A\left(z_{1,1}, z_{2,1}, z_{3,2}\right)$ & $B\left(z_{1,1}, z_{2,1}, z_{3,2}\right)$ & $F_{1,1}(x) F_{2,1}(x) F_{3,2}(x)$ \\
3 & $(1,2,1)$ & $A\left(z_{1,1}, z_{2,2,}, z_{3,1}\right)$ & $B\left(z_{1,1}, z_{2,2,}, z_{3,1}\right)$ & $F_{1,1}(x) F_{2,2}(x) F_{3,1}(x)$ \\
4 & $(1,2,2)$ & $A\left(z_{1,1}, z_{2,2}, z_{3,2}\right)$ & $B\left(z_{1,1}, z_{2,2,}, z_{3,2}\right)$ & $F_{1,1}(x) F_{2,2}(x) F_{3,2}(x)$ \\
5 & $(2,1,1)$ & $A\left(z_{1,2}, z_{2,1}, z_{3,1}\right)$ & $B\left(z_{1,2,} z_{2,1}, z_{3,1}\right)$ & $F_{1,2}(x) F_{2,1}(x) F_{3,1}(x)$ \\
6 & $(2,1,2)$ & $A\left(z_{1,2}, z_{2,1}, z_{3,2}\right)$ & $B\left(z_{1,2,}, z_{2,1}, z_{3,2}\right)$ & $F_{1,2}(x) F_{2,1}(x) F_{3,2}(x)$ \\
7 & $(2,2,1)$ & $A\left(z_{1,2}, z_{2,2}, z_{3,1}\right)$ & $B\left(z_{1,2}, z_{2,2,}, z_{3,1}\right)$ & $F_{1,2}(x) F_{2,2}(x) F_{3,1}(x)$ \\
8 & $(2,2,2)$ & $A\left(z_{1,2}, z_{2,2}, z_{3,2}\right)$ & $B\left(z_{1,2,}, z_{2,2,}, z_{3,2}\right)$ & $F_{1,2}(x) F_{2,2}(x) F_{3,2}(x)$
\end{tabular}

After this example it is interesting to present a systematic way of constructing the matrices $A_{i}$ and $B_{i}$. For example, to determine $A_{3}$ and $B_{3}$, the triplet $\sigma_{3}=(1,2,1)$ is used. This triplet codes the variable partitions occurring in the 3rd submodel and $\sigma_{3}^{k}$ denotes the $k$ th value in the triplet $\sigma_{3}$. According to the expression of $A_{3}$ and $B_{3}$, these matrices may be noted: $A_{3}=$ $A\left(z_{1, \sigma_{3}}{ }^{1}, z_{3, \sigma_{3}}{ }^{3}\right)$ and $B_{3}=B\left(z_{2, \sigma_{3}}{ }^{2}\right)$, where $z_{1, \sigma_{3}}{ }^{1}, z_{2, \sigma_{3}{ }^{2}}$ and $z_{3, \sigma_{3}}{ }^{3}$ are the scalars defined in eq 9. In a more general way, $A_{i}$ and $B_{i}$ $(i=1, \ldots, 8)$ are noted:

$$
\begin{aligned}
& A_{i}=A\left(z_{1, \sigma_{i}}, z_{3, \sigma_{i}^{3}}\right) \\
& B_{i}=B\left(z_{2, \sigma_{i}^{2}}\right)
\end{aligned}
$$

Those notations are in agreement with eq 13. Associated to $A_{3}$ and $B_{3}$, the definition of eq 10 is obtained by using the triplet $\sigma_{3}$. Indeed:

$$
\mu_{3}(x)=F_{1, \sigma_{3}{ }^{1}}(x) F_{2, \sigma_{3}{ }^{2}}(x) F_{3, \sigma_{3}{ }^{3}}(x)
$$

Table 1 details the construction of all submodels $\left(A_{i}, B_{i}\right)$ and the weighting functions $\mu_{i}(x)$ of a $\mathrm{MM}$ with three premise variables.

Each function defining a premise variable being partitioned into two functions, there are $2^{3}$ submodels and $2^{3}$ weighting functions. To each submodel $i$ corresponds a triplet $\sigma_{i}$ which codes the variable partitions occurring in it. After multiplying the functions representing these partitions, the weighting function $\mu_{i}(x)$ corresponding to the $i$ th submodel is obtained.

To express the constant matrices $A_{i}$ and $B_{i}$, characterizing each submodel $i(i=1, \ldots, 8)$, we use the quasi-LPV form 6 of the system (eq 3 ), where $A(x, u)$ and $B(x, u)$ were defined in 6 .

In the next section, the proposed methodology applied to the example of this section section will be generalized to any nonlinear systems.

The General Case. A large category of dynamic nonlinear systems can be represented by

$$
\left\{\begin{array}{l}
\dot{x}(t)=f(x(t), u(t)) \\
y(t)=g(x(t), u(t))
\end{array}\right.
$$

where $f(x(\cdot), u(\cdot)) \in \mathbb{R}^{n}$ and $g(x(\cdot), u(\cdot)) \in \mathbb{R}^{l}$.

Under the hypothesis that $f(x(t), u(t))$ and $g(x(t), u(t))$ are continuous and bounded in $U \subseteq \mathbb{R}^{n}$ with $f(0, \cdot)=0$ and $g(0, \cdot)$ $=0$, the system eq 15 can be represented in a quasi-LPV form:

$$
\left[\begin{array}{l}
\dot{x}(t) \\
y(t)
\end{array}\right]=\left[\begin{array}{ll}
A(\rho(x, u)) & B(\rho(x, u)) \\
C(\rho(x, u)) & D(\rho(x, u))
\end{array}\right]\left[\begin{array}{l}
x(t) \\
u(t)
\end{array}\right]
$$

where $A(\rho(x, u)) \in \mathbb{R}^{n \times n}, B(\rho(x, u)) \in \mathbb{R}^{n \times m}, C(\rho(x, u)) \in \mathbb{R}^{l \times n}$, $D(\rho(x, u)) \in \mathbb{R}^{l \times m}$ and where $\rho(x, u) \in C^{1}\left(\mathbb{R}^{n+m}, \mathbb{R}^{n_{1}+m_{1}}\right)$ with $n_{1}$ $+m_{1} \leq n+m$ can simply represent a part of the state and input variables. Let us remember that in the classical LPV form, the parameter vector $\rho$ explicitly depends on the time variable only. Then, the quasi-LPV representation of a nonlinear system is different from the classical LPV form in that the underlying parameters $\rho$ are now functions of the state and input variables. ${ }^{22}$ The trajectory of the parameters is actually determined by the behavior of the system variables. For example, in the introductory example, 6 is a quasi-LPV form in which the matrix $A$ depends on $x=\left(x_{1}, x_{2}\right)$, so the vector $\rho(x, u)=x$ and the matrix $B$ depends only on $x_{1}$, so the vector $\rho(x, u)=x_{1}$.

It has to be remarked that the quasi-LPV 16 form represents a state and control affine representation of a general nonlinear system.

The matrix function $A(\rho(x, u))$ is in this case given by

$$
A(\rho(x, u))=\left[\begin{array}{lll}
a_{1,1}(\rho(x, u)) & \cdots & a_{1, n}(\rho(x, u)) \\
\vdots & & \\
a_{n, 1}(\rho(x, u)) & \cdots & a_{n, n}(\rho(x, u))
\end{array}\right]
$$

The matrices $B(\rho(x, u)), C(\rho(x, u))$, and $D(\rho(x, u))$ are given in the same way as $A(\rho(x, u))$.

Presenting the nonlinear system 15 in a quasi-LPV form 16 amounts to expressing each state component $x_{i}(t)$ and each output component $y_{j}(t)$ in the following way:

$$
\begin{aligned}
& \dot{x}_{i}(t)=\sum_{q=1}^{n} a_{i, q}(\rho(x, u)) x_{q}(t)+\sum_{s=1}^{m} b_{i, s}(\rho(x, u)) u_{s}(t) \\
& y_{j}(t)=\sum_{q=1}^{n} c_{j, q}(\rho(x, u)) x_{q}(t)+\sum_{s=1}^{m} d_{j, s}(\rho(x, u)) u_{s}(t)
\end{aligned}
$$

for all $i=1, \ldots, n$ and $j=1, \ldots, l$. This explicit quasi-LPV form 16 realizes a repartition of the system nonlinearities $\left(a_{i, q}, b_{i, s}\right.$, $\left.c_{j, q}, d_{j, s}\right)$ and the different state or input components.

Considering the quasi-LPV form 16, we define the premise variable set $V_{z}$ in the following way:

$$
\begin{gathered}
V_{z}=\left\{a_{i, q}(\rho(x, u)) \mid a_{i, q} \neq \text { const }, i=\overline{1, n}, \quad q=\overline{1, n}\right\} \\
\cup\left\{b_{i, s}(\rho(x, u)) \mid b_{i, s} \neq \text { const }, i=\overline{1, n}, \quad s=\overline{1, m}\right\} \\
\cup\left\{c_{j, q}(\rho(x, u)) \mid c_{j, q} \neq \text { const }, j=\overline{1, l}, \quad q=\overline{1, n}\right\} \\
\cup\left\{d_{j, s}(\rho(x, u)) \mid d_{j, s} \neq \text { const }, j=\overline{1, l}, \quad s=\overline{1, m}\right\}
\end{gathered}
$$

where $\overline{1, n}=\{1, \ldots, n\}$.

Subsequently, this set is noted more simply:

$$
V_{z}=\left\{z_{1}(\rho(x, u)), \ldots, z_{p}(\rho(x, u)) \mid p \leq(n+l) \times(n+m)\right\}
$$

where $p$ represents the dimension of the premise variable set $V_{z}$ and is also the number of nonlinearities identified using the quasiLPV form of the system 15 . The quantities $z_{1}(\rho(x, u)), \ldots, z_{p}(\rho(x, u))$ are the premise variables.

Remark 1. $(n+l) \times(n+m)$ represents the largest number of premise variables.

Remark 2. The number of submodels that constitute the multiple model is equal to $r=2^{p} \leq 2^{(n+l)(n+m)}$.

The matrices with variable parameters intervening in the quasi-LPV form of system 15 are linear combinations of matrices with constant coefficients $\left(\mathscr{C}_{j}, \mathscr{B}_{j}, \mathscr{O}_{j}, \mathscr{D}_{j}\right)$; for example, the matrix $A(x, u)$ may be expressed in the following way:

$$
A(x, u)=\mathscr{A}_{0}+\sum_{j \in \mathscr{T}_{A}} z_{j}(x, u) \mathscr{A}_{j}
$$

The set $\mathscr{T}_{A}$ contains all the indices corresponding to the premise variables which are contained in the entries of the matrix $A(x, u)$. The matrix $\mathscr{A}_{0}$ contains the constant entries $\left(a_{i, j}\right)$ of the 


\begin{tabular}{|c|c|c|c|c|}
\hline submodel $i$ & $\sigma_{i}$ & $A_{i}$ & $B_{i}$ & $\mu_{i}(z)$ \\
\hline $\begin{array}{l}1 \\
2 \\
\vdots \\
2^{p-1}\end{array}$ & $\begin{array}{l}(1,1, \ldots, 1) \\
(1,1, \ldots, 2) \\
\vdots \\
(1,2, \ldots, 2)\end{array}$ & $\begin{array}{l}A\left(z_{1,1}, z_{2,1}, \ldots, z_{p, 1}\right) \\
A\left(z_{1,1}, z_{2,1}, \ldots, z_{p, 2}\right) \\
\vdots\end{array}$ & $\begin{array}{l}B\left(z_{1,1}, z_{2,1}, \ldots, z_{p, 1}\right) \\
B\left(z_{1,1}, z_{2,1}, \ldots, z_{p, 2}\right) \\
\vdots\end{array}$ & $\begin{array}{l}\prod_{j=1}^{p} F_{j, \sigma_{1}^{j}} \\
\prod_{j=1}^{p} F_{j, \sigma_{2}^{j}} \\
\vdots\end{array}$ \\
\hline $2^{p-1}+1$ & $\begin{array}{l}(2,1, \ldots, 1) \\
(2,1, \ldots, 2)\end{array}$ & $A\left(z_{1,2}, z_{2,1}, \ldots, z_{p, 1}\right)$ & $B\left(z_{1,2}, z_{2,1}, \ldots, z_{p, 1}\right)$ & $\prod_{j=1}^{p} F_{j, \sigma} j_{\left(2^{p-1}+1\right)}^{j}$ \\
\hline
\end{tabular}

matrix $A(x, u)$. Each matrix $\mathscr{A}_{j}$ gives the linear dependency of $A(x, u)$ to $z_{j}$ and contains at the position corresponding to the nonlinearity $a_{i, q}$ (identified with the premise variable $z_{j}$ ) the constant term 1 , and zero for all the other positions:

$$
\mathcal{L}_{j}=\left[\begin{array}{ccccc}
0 & \cdots & 0 & \cdots & 0 \\
& & \vdots & & \\
0 & \cdots & 1 & \cdots & 0 \\
& & \vdots & & \\
0 & & 0 & & 0
\end{array}\right] i
$$

The matrices $B(x, u), C(x, u), D(x, u)$ are expressed in the same way as $A(x, u)$ using the sets $\mathscr{T}_{B}, \mathscr{T}_{C}$, and $\mathscr{T}_{D}$. In this way, for the previous example (eq 6) we have $\mathscr{T}_{A}=\{1,3\}$ and $\mathscr{T}_{B}=\{2\}$.

By generalizing the presented method in the introductory example, we generate the $2^{p}$ submodels of a multiple model characterized by the $p$ premise variables which are partitioned into two, using the convex polytopic transformation:

$$
z_{j}(x, u)=F_{j, 1}\left(z_{j}\right) z_{j, 1}+F_{j, 2}\left(z_{j}\right) z_{j, 2}
$$

with

$$
\begin{aligned}
& F_{j, 1}\left(z_{j}\right)=\frac{z_{j}(x, u)-z_{j, 2}}{z_{j, 1}-z_{j, 2}} \\
& F_{j, 2}\left(z_{j}\right)=\frac{z_{j, 1}-z_{j}(x, u)}{z_{j, 1}-z_{j, 2}}
\end{aligned}
$$

where the scalars $z_{j, 1}$ and $z_{j, 2}$ are defined in eq 22 :

$$
\begin{aligned}
z_{j, 1} & =\max _{x, u}\{Z j(x, u)\} \\
z_{j, 2} & =\min _{x, u}\{Z j(x, u)\}
\end{aligned} \forall j=1, \ldots, p
$$

To each submodel $i$, represented in Table 2 by the $i$ th line, corresponds a $p$-uplet $\sigma_{i}$ which codes the partitions of premise variables intervening in the corresponding weighting function. It is thus possible to construct, just like in the previous example, a table gathering the partition sets of premise variables. By multiplying the functions that represent these partitions we obtain the corresponding weighting function $\mu_{i}(z)$ :

$$
\mu_{i}(z)=\prod_{j=1}^{p} F_{j, \sigma_{i}}\left(z_{j}(x, u)\right)
$$

where $\sigma_{i}^{k}$ represents the index in the $k$ th position in the $p$-uplet $\sigma_{i}$. Then $\sum_{i=1}^{r} \mu_{i}(z)=1$ and $\mu_{i}(z) \geq 0(i=1, \ldots, r)$, because

$$
F_{j, 1}\left(z_{j}(x, u)\right)+F_{j, 2}\left(z_{j}(x, u)\right)=1, \quad \forall j=1, \ldots, p
$$

We have to note that the matrices $A(x, u), B(x, u), C(x, u)$, and $D(x, u)$ contain the premise variables $z_{j}$ for $j=1, \ldots, p$. In this way, the matrices $A, B, C$, and $D$ will be evaluated in the vertices of the polytope defined by the premise variable partitions that occur in these matrices in order to determine the matrices $A_{i}$, $B_{i}, C_{i}$, and $D_{i}(i=1, \ldots, r)$. These matrices are the matrices with constant coefficients relative to each submodel:

$$
A_{i}=\mathscr{A}_{0}+\sum_{j \in \mathscr{T}_{A}} z_{j, \sigma_{i}^{j}} \mathscr{A}_{j}
$$

$B_{i}, C_{i}$, and $D_{i}$ can be written in the same way. This fact is detailed in the demonstration of the following theorem:

Theorem 2. The multiple model eq 1 , which represents a convex combination of linear subsystems, $\left\{\left(A_{i}, B_{i}, C_{i}, D_{i}\right)\right\}$ $(i=1, \ldots, r)$, is equivalent to the system $16 ; r=2^{p}$ is the number of submodels and $p$ is the number of premise variables.

Proof. We first want to prove that the matrices $A_{i}(i=1, \ldots, r)$, representing the $r$ submodels of the multiple model, are calculated by evaluating the matrix function $A$ in the polytope vertex defined by the premise variable partitions.

As already mentioned in eq 19

$$
A(z)=\mathscr{A}_{0}+\sum_{j=1}^{p} z_{j} \iota_{j}
$$

After replacing $z_{p}$ (like in 20 for $j=p$ ) in the previous equality eq 25 and multiplying the other terms of the sum by $F_{p, 1}+F_{p, 2}$ $=1$, we obtain

$$
A(z)=\left(F_{p, 1}+F_{p, 2}\right)\left(\mathcal{l}_{0}+\sum_{j=1}^{p-1} z_{j} \mathcal{l}_{j}\right)+\left(z_{p, 1} F_{p, 1}+z_{p, 2} F_{p, 2}\right) \cdot \mathcal{l}_{p}
$$

We then factor the terms that contain $F_{p, 1}$ and $F_{p, 2}$ and we obtain

$$
\begin{aligned}
& A(z)=F_{p, 1}\left(\mathscr{L}_{0}+\sum_{j=1}^{p-1} z_{j} \mathcal{l}_{j}+z_{p, 1} \mathcal{L}_{p}\right)+ \\
& F_{p, 2}\left(\mathscr{C}_{0}+\sum_{j=1}^{p-1} z_{j} \mathscr{l}_{j}+z_{p, 2} \mathscr{C}_{p}\right)
\end{aligned}
$$

After replacing $z_{p-1}$ (like in 20 for $j=p-1$ ) and after multiplying the other terms of the sum by $F_{p-1,1}+F_{p-1,2}=1$, we obtain:

$$
\begin{aligned}
A(z) & =F_{p, 1} \cdot\left[\left(F_{p-1,1}+F_{p-1,2}\right)\left(\mathcal{l}_{0}+\sum_{j=1}^{p-2} z_{j} \mathcal{l}_{j}\right)\right. \\
& +\left(z_{p-1,1} F_{p-1,1}+z_{p-1,2} F_{p-1,2}\right) \cdot \mathcal{l}_{p-1} \\
& \left.+z_{p, 1}\left(F_{p-1,1}+F_{p-1,2}\right) \mathcal{l}_{p}\right] \\
& +F_{p, 2} \cdot\left[\left(F_{p-1,1}+F_{p-1,2}\right)\left(\mathscr{l}_{0}+\sum_{j=1}^{p-2} z_{j} \mathcal{l}_{j}\right)\right. \\
& +\left(z_{p-1,1} F_{p-1,1}+z_{p-1,2} F_{p-1,2}\right) \cdot \mathscr{l}_{p-1} \\
& \left.+z_{p, 2}\left(F_{p-1,1}+F_{p-1,2}\right) \mathscr{l}_{p}\right]
\end{aligned}
$$

After factoring again the terms that contain $F_{p-1,1}$ and $F_{p-1,2}$, inside the brackets we obtain 


$$
\begin{aligned}
& A(z)=F_{p, 1} F_{p-1,1}\left[\mathscr{C}_{0}+\sum_{j=1}^{p-2} z_{j} \mathscr{l}_{j}+z_{p-1,1} \mathscr{C}_{p-1}+z_{p, 1} \mathcal{A}_{p}\right] \\
& +F_{p, 1} F_{p-1,2}\left[\mathcal{l}_{0}+\sum_{j=1}^{p-2} z_{j} \mathcal{L}_{j}+z_{p-1,2} \mathcal{L}_{p-1}+z_{p, 1} \mathcal{L}_{p}\right] \\
& +F_{p, 2} F_{p-1,1}\left[\mathscr{l}_{0}+\sum_{j=1}^{p-2} z_{j} \mathscr{l}_{j}+z_{p-1,1} \mathcal{L}_{p-1}+z_{p, 2} \mathcal{A}_{p}\right] \\
& +F_{p, 2} F_{p-1,2}\left[\mathscr{l}_{0}+\sum_{j=1}^{p-2} z_{j} \mathscr{l}_{j}+z_{p-1,2} \mathscr{l}_{p-1}+z_{p, 2} \mathscr{l}_{p}\right]
\end{aligned}
$$

By reiterating this factorization mechanism and replacing at each step $z_{j}$ with the expression 20, until we have replaced all the premise variables, we obtain-

$$
A(z)=\sum_{i=1}^{2^{p}}\left\{\prod_{j=1}^{p} F_{j, \sigma_{i}} \cdot\left[\mathcal{L}_{0}+\sum_{j=1}^{p} z_{j, \sigma_{i}} \cdot \mathcal{l}_{j}\right]\right\}
$$

We succeeded in expressing the matrices $A_{i}(i=1, \ldots, r)$ by using the polytope vertices defined by the premise variable partitions:

$$
A_{i}=\mathscr{A}_{0}+\sum_{j=1}^{p} z_{j, \sigma_{i}^{i}} \cdot \mathscr{A}_{j}
$$

After applying the same reasoning for the input and output parts, we proved in this way the equivalence between the multiple model 1 and the system 15 .

In the next subsection will be given some general tools concerning the observer/controller design based on MM structure, in order to support the general analytical method and motivate the choice of the final MM structure.

\section{Choice Criteria for Quasi-LPV Form}

The existing results concerning the performance analysis and the synthesis of controller/observer for a multiple model $^{14,15,19,16,21,23-26}$ are based on the resolution of linear matrix inequalities (LMI), by using the Lyapunov method. Because of the convex sum property of the weighting functions, the LMI are only evaluated at the polytope vertices $\left(A_{i}, B_{i}\right)$ and the weighting functions do not occur in the resolution of the LMIs. Only the matrices $A_{i}$ and $B_{i}$ have a contribution in the resolution of the LMIs. It is important to mention that the LMI formulation of controller or observer design for MM consists only in sufficient but not necessary conditions. That is the reason why it is essential to propose choice criteria for the MM structure.

In general, the quasi-LPV form 16 for a nonlinear system 15 is not unique; to each quasi-LPV form corresponds a particular premise variables set; choosing a quasi-LPV form is equivalent to choosing the premise variable set. The choice of premise variable set $V_{z}$ is important, because it has an influence on the submodel number and on the global model structure. This is a degree of freedom that can be used to ease the controllability, observability, and stability analysis studies.

First of all, to ensure the controllability/observability of the global system, represented in a multiple model form, that is, to ensure a solution for the LMIs associated to the MM in order to compute the controller/the observer, the controllability/ observability of each submodel is necessary. ${ }^{23}$ Thus, the quasiLPV forms producing submodels that are not controllable/ observable must be eliminated. Note that this is not a sufficient condition to ensure the controllability/observability of the multiple model ${ }^{28}{ }^{2}$ For instance, the different quasi-LPV forms of the system eq 3 in the introductory example do not share the same structure. The form 5 implies a null matrix $B(z)$, thus the multiple model cannot be controllable, whereas in eqs 4 and 6 the matrix $B(z)$ is non-null and therefore the necessary controllability condition of these multiple models is verified.

As said before, in the stability analysis studies of multiple models, the observer stability conditions are given in terms of linear matrix inequalities (LMI). Different techniques are proposed to reduce the number of LMI conditions, which leads to less computational requirements ${ }^{24}$ and eases the solution existence. ${ }^{26}$ As a consequence, the number of LMI to be satisfied is linear or polynomial in the number of submodels. ${ }^{16}$ That is the reason why a multiple model composed by a low number of submodels is searched. This number is related to the number of premise variables, so that a quasi-LPV form which has a small set of premise variables will be preferred. For example, the quasi-LPV forms 4 and 5 implies four premise variables and will thus lead to 16 submodels, whereas the form 6 only requires three premise variables and then eight submodels. In addition to that, the observer/controller design for MM with premise variables depending on the state variables is a lot more complex than if the premise variables are known. ${ }^{27}$ As a consequence, $\mathrm{MM}$ form with premise variables depending on a minimal number of state variables is preferable.

To increase the probability that a solution exists, the dimension of the state vector should be made as small as possible. ${ }^{25}$ Taking into account the previous remarks, the following rules can guide the choice of the quasi-LPV form leading to the most appropriate model:

(i) Eliminate all quasi-LPV forms in which the matrix $B$ has null columns and the matrix $C$ has null rows, since these matrices do not respect the rank observability/controllability conditions. Indeed, retain all quasi-LPV forms in which matrices satisfy the conditions

$$
\begin{aligned}
\operatorname{rank}\left(\Theta_{i}\right)=\operatorname{rank}\left[\begin{array}{l}
C_{i} \\
C_{i} A_{i} \\
\vdots \\
C_{i} A_{i}^{n-1}
\end{array}\right]=n \\
\operatorname{rank}\left(O_{i}\right)=\operatorname{rank}\left[\begin{array}{llll}
B_{i} & A_{i} B_{i} & \ldots & A_{i}^{n-1} B_{i}
\end{array}\right]=n, \quad \forall i=1, \ldots, r
\end{aligned}
$$

(ii) Among all quasi-LPV forms for which the premise variables $z_{i}(\rho(x, u))(i=1, \ldots, p)$ depend on the same number of state variables, choose the quasi-LPV form that contains the lowest number of premise variables $z_{i}(\rho(x, u))$ (taking into account the next rule).

(iii) Identify the decompositions that relate on the same premise variables for different state and/or output eqs 18, reducing in this way the number of premise variables.

(iv) Among all quasi-LPV forms that have the same number of premise variables $z_{i}(\rho(x, u))(i=1, \ldots, p)$, choose the quasiLPV form for which the premise variables $z_{i}(\rho(x, u))$ depend on the lowest number of state variables.

\section{Application to an Activated Sludge Reactor Model}

In this section, the analytical decomposition method developed in the previous section will be applied to an activated sludge reactor model, a reduced form of the ASM1 model, considering only the carbon pollution. ${ }^{17}$ 


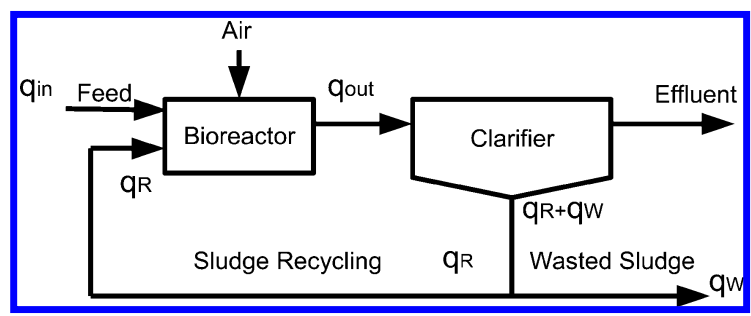

Figure 1. The diagram of activated sludge wastewater treatment process.

Table 3. Table of Variables

\begin{tabular}{|c|c|c|c|c|}
\hline variable & definition & $\begin{array}{c}\text { reactor } \\
\text { input }\end{array}$ & $\begin{array}{r}\text { reactor } \\
\text { output }\end{array}$ & recycled \\
\hline$X_{\mathrm{BH}}$ & $\begin{array}{l}\text { heterotrophic biomass } \\
\text { concentration }\end{array}$ & $X_{\mathrm{BH}, \text { in }}$ & $X_{\mathrm{BH}, \text { out }}$ & $X_{B H, R}$ \\
\hline$S_{\mathrm{S}}$ & $\begin{array}{l}\text { fast biodegradable } \\
\text { substrate concentration }\end{array}$ & $S_{\mathrm{S}, \text { in }}$ & $S_{\mathrm{S} \text {,out }}$ & $S_{S, R}$ \\
\hline$S_{\mathrm{O}}$ & $\begin{array}{l}\text { dissolved oxygen } \\
\text { concentration }\end{array}$ & $S_{\text {O,in }}$ & $S_{\mathrm{O} \text {,out }}$ & $S_{\mathrm{O}, \mathrm{R}}$ \\
\hline $\begin{array}{l}q \\
V \\
q\end{array}$ & $\begin{array}{l}\text { flow } \\
\text { reactor volume } \\
\text { air flow }\end{array}$ & $q_{\text {in }}$ & $q_{\text {out }}$ & $q_{\mathrm{R}}$ \\
\hline
\end{tabular}

The wastewater treatment using activated sludge consists in mixing used waters with a rich mixture of bacteria in order to degrade the organic matter. In studies on the activated sludge reactor, several operating modes are considered: regulation from a reference volume, reactor with constant volume, free flow at the output reactor, and controllable input and output flows. Only the first situation using a reference volume is reported here.

Biomass, Carbon and Oxygen Modeling in an Aerobic Environment. Considering only the carbon pollution of an activated sludge reactor, the elimination process of this pollutant is realized in the reactor-clarifier group. The simplified diagram of the studied process is given in Figure 1. The clarifier is supposed to be perfect, that is, with no internal dynamic process and no biomass in the effluent. In this case we can write at each time instant:

$$
\begin{gathered}
\left(q_{\mathrm{in}}+q_{\mathrm{R}}\right) X_{\mathrm{BH}}=\left(q_{\mathrm{R}}+q_{\mathrm{W}}\right) X_{\mathrm{BH}, \mathrm{R}} \\
S_{\mathrm{S}, \mathrm{R}}=S_{\mathrm{S}}
\end{gathered}
$$

where $q_{\text {in }}, q_{\mathrm{R}}, q_{\mathrm{W}}$ represent respectively the input, recycled, and wasted flow and where $X_{\mathrm{BH}}, X_{\mathrm{BH}, \mathrm{R}}, S_{\mathrm{S}}$ and $S_{\mathrm{S}, \mathrm{R}}$ are different concentrations whose meaning is pointed in Table 3 .

The whole process can be represented by the following nonlinear model:

$$
\left\{\begin{array}{l}
\frac{\mathrm{d} V}{\mathrm{~d} t}=q_{\mathrm{in}}+q_{\mathrm{R}}-q_{\text {out }} \\
\frac{\mathrm{d}\left(V \cdot X_{\mathrm{BH}}\right)}{\mathrm{d} t}=q_{\mathrm{in}} X_{\mathrm{BH}, \text { in }}+q_{\mathrm{R}} X_{\mathrm{BH}, \mathrm{R}}-q_{\text {out }} X_{\mathrm{BH}, \text { out }}+r_{\mathrm{H}} V \\
\frac{\mathrm{d}\left(V \cdot S_{\mathrm{S}}\right)}{\mathrm{d} t}=q_{\mathrm{in}} S_{\mathrm{S}, \text { in }}+q_{\mathrm{R}} S_{\mathrm{S}, \mathrm{R}}-q_{\text {out }} S_{\mathrm{S}, \text { out }}+r_{\mathrm{S}} V \\
\frac{\mathrm{d}\left(V \cdot S_{\mathrm{O}}\right)}{\mathrm{d} t}=q_{\mathrm{in}} S_{\mathrm{O}, \text { in }}+q_{\mathrm{R}} S_{\mathrm{O}, \mathrm{R}}-q_{\mathrm{out}} S_{\mathrm{O}, \text { out }}+r_{\mathrm{O}} V+ \\
K q_{\mathrm{a}} V\left(S_{\mathrm{O}, \text { sat }}-S_{\mathrm{O}}\right)
\end{array}\right.
$$

where the variables involved are presented in Table 3 and $r_{\mathrm{H}}$, $r_{\mathrm{S}}$, and $r_{\mathrm{O}}$ represent the kinetics of heterotrophic biomass $X_{\mathrm{BH}}$, carbon $S_{\mathrm{S}}$, and oxygen $S_{\mathrm{O}}$ reactions, in a heterotroph and aerobic environment and are modeled by

$$
\left\{\begin{array}{l}
r_{\mathrm{H}}=\mu_{\mathrm{H}} \frac{S_{\mathrm{S}}}{K_{\mathrm{S}}+S_{\mathrm{S}}} \frac{S_{\mathrm{O}}}{K_{\mathrm{OH}}+S_{\mathrm{O}}} X_{\mathrm{BH}}-b_{\mathrm{H}} X_{\mathrm{BH}} \\
r_{\mathrm{S}}=-\frac{1}{Y_{\mathrm{H}}} \mu_{\mathrm{H}} \frac{S_{\mathrm{S}}}{K_{\mathrm{S}}+S_{\mathrm{S}}} \frac{S_{\mathrm{O}}}{K_{\mathrm{OH}}+S_{\mathrm{O}}} X_{\mathrm{BH}}+(1-f) b_{\mathrm{H}} X_{\mathrm{BH}} \\
r_{\mathrm{O}}=\frac{Y_{\mathrm{H}}-1}{Y_{\mathrm{H}}} \mu_{\mathrm{H}} \frac{S_{\mathrm{S}}}{K_{\mathrm{S}}+S_{\mathrm{S}}} \frac{S_{\mathrm{O}}}{K_{\mathrm{OH}}+S_{\mathrm{O}}} X_{\mathrm{BH}}
\end{array}\right.
$$

The different coefficients occurring in eq 29 and eq 30 are presented in Table 4.

Under the reactor homogeneity hypothesis, the following assumptions are often made: ${ }^{17}$

$$
\left\{\begin{array}{l}
X_{\mathrm{BH}, \text { out }}=X_{\mathrm{BH}} \\
S_{\mathrm{S}, \text { out }}=S_{\mathrm{S}} \\
S_{\mathrm{O}, \text { out }}=S_{\mathrm{O}}
\end{array}\right.
$$

In general, $q_{\mathrm{R}}$ and $q_{\mathrm{W}}$ represent fractions of input flow $q_{\mathrm{in}}$ :

$$
\begin{array}{ll}
q_{\mathrm{R}}=f_{\mathrm{R}} q_{\text {in }}, & 1 \leq f_{\mathrm{R}} \leq 2 \\
q_{\mathrm{W}}=f_{\mathrm{W}} q_{\mathrm{in}}, & 0<f_{\mathrm{W}}<1
\end{array}
$$

We suppose that the dissolved oxygen concentration at the reactor input $\left(S_{\mathrm{O}, \mathrm{in}}\right)$ is null.

The system 29 becomes in this case:

$$
\left\{\begin{array}{l}
\dot{V}=q_{\text {in }}+q_{\mathrm{R}}-q_{\mathrm{out}} \\
\dot{X}_{\mathrm{BH}}=\frac{q_{\text {in }}}{V} X_{\mathrm{BH}, \text { in }}-\frac{q_{\mathrm{W}}}{V} \frac{q_{\text {in }}+q_{\mathrm{R}}}{q_{\mathrm{W}}+q_{\mathrm{R}}} X_{\mathrm{BH}}+r_{\mathrm{H}} \\
\dot{S}_{\mathrm{S}}=\frac{q_{\text {in }}}{V}\left(S_{\mathrm{S}, \text { in }}-S_{\mathrm{S}}\right)+r_{\mathrm{S}} \\
\dot{S}_{\mathrm{O}}=-\frac{q_{\text {in }}}{V} S_{\mathrm{O}}+K q_{\mathrm{a}}\left(S_{\mathrm{O}, \text { sat }}-S_{\mathrm{O}}\right)+r_{\mathrm{O}}
\end{array}\right.
$$

Regulation from a Reference Volume. Hereafter, it is assumed that the volume is controlled in order to obtain $V$ equal $V_{\text {ref. }}$ To regulate the output $q_{\text {out }}$ the control law combining a priori/a posteriori control is defined by

$$
q_{\text {out }}=\left(f_{\mathrm{R}}+1\right) q_{\mathrm{in}}-K_{1}\left(V_{\text {ref }}-V\right)
$$

The control variables are the air flow $\left(q_{\mathrm{a}}\right)$, the recycled flow $\left(q_{\mathrm{R}}\right)$, and the rejected flow $\left(q_{\mathrm{W}}\right)$. In this case, the state and input vectors are defined by

$$
\begin{gathered}
x=\left[V X_{\mathrm{BH}} S_{\mathrm{S}} S_{\mathrm{O}}\right]^{\mathrm{T}} \\
u=\left[X_{\mathrm{BH}, \text { in }} S_{\mathrm{S}, \text { in }} q_{\mathrm{a}} V_{\mathrm{ref}}\right]^{\mathrm{T}}
\end{gathered}
$$

After replacing $r_{\mathrm{H}}, r_{\mathrm{S}}$, and $r_{\mathrm{O}}$ given in eq 30 , the system 31 becomes:

\section{Table 4. Table of Constants}

$\begin{array}{ll}S_{\mathrm{O}, \text { sat }} & \text { oxygen saturation concentration } \\ K_{\mathrm{S}}, K_{\mathrm{OH}} & \text { half-saturation constants } \\ Y_{\mathrm{H}} & \text { yield coefficient for heterotrophic biomass } \\ f & \text { fraction of biomass leading to particulate products } \\ b_{\mathrm{H}}, \mu_{\mathrm{H}} & \text { heterotrophic kinetic coefficients } \\ K & \text { regulator gain in oxygen }\end{array}$




$$
\begin{gathered}
\dot{V}=K_{1}\left(V_{\mathrm{ref}}-V\right) \\
\dot{X}_{\mathrm{BH}}=\frac{q_{\mathrm{in}}}{V} X_{\mathrm{BH}, \mathrm{in}}-\frac{q_{\mathrm{W}}}{V} \frac{q_{\mathrm{in}}+q_{\mathrm{R}}}{q_{\mathrm{W}}+q_{\mathrm{R}}} X_{\mathrm{BH}}+ \\
\mu_{\mathrm{H}} \frac{S_{\mathrm{S}}}{K_{\mathrm{S}}+S_{\mathrm{S}}} \frac{S_{\mathrm{O}}}{K_{\mathrm{OH}}+S_{\mathrm{O}}} X_{\mathrm{BH}}-b_{\mathrm{H}} X_{\mathrm{BH}} \\
\dot{S}_{\mathrm{S}}=\frac{q_{\mathrm{in}}}{V}\left(S_{\mathrm{S}, \mathrm{in}}-S_{\mathrm{S}}\right)+(1-f) b_{\mathrm{H}} X_{\mathrm{BH}}- \\
\frac{\mu_{\mathrm{H}}}{Y_{\mathrm{H}}} \frac{S_{\mathrm{S}}}{K_{\mathrm{S}}+S_{\mathrm{S}}} \frac{S_{\mathrm{O}}}{K_{\mathrm{OH}}+S_{\mathrm{O}}} X_{\mathrm{BH}} \\
\dot{S}_{\mathrm{O}}=-\frac{q_{\mathrm{in}}}{V} S_{\mathrm{O}}+K q_{\mathrm{a}}\left(S_{\mathrm{O}, \mathrm{sat}}-S_{\mathrm{O}}\right)+ \\
\frac{Y_{\mathrm{H}}-1}{Y_{\mathrm{H}}} \mu_{\mathrm{H}} \frac{S_{\mathrm{S}}}{K_{\mathrm{S}}+S_{\mathrm{S}}} \frac{S_{\mathrm{O}}}{K_{\mathrm{OH}}+S_{\mathrm{O}}} X_{\mathrm{BH}}
\end{gathered}
$$

To put this nonlinear system into a multiple model form, each state equation first has to be presented in a quasi-LPV form like eq 18. Then, taking into account eq 32 and eq 33, the matrices are defined as follows:

$$
\begin{aligned}
A\left(z_{1}, z_{2}, z_{3}\right) & =\left(\begin{array}{llll}
a_{1,1} & 0 & 0 & 0 \\
0 & a_{2,2} & 0 & 0 \\
0 & a_{3,2} & a_{3,3} & 0 \\
0 & a_{4,2} & 0 & a_{4,4}
\end{array}\right) \\
B\left(z_{2}\right) & =\left(\begin{array}{lllll}
0 & 0 & 0 & b_{1,4} \\
b_{2,1} & 0 & 0 & 0 \\
0 & b_{3,2} & 0 & 0 \\
0 & 0 & b_{4,3} & 0
\end{array}\right)
\end{aligned}
$$

where

$$
\begin{aligned}
& a_{1,1}=-K_{1} \\
& a_{2,2}=\mu_{\mathrm{H}} z_{1}-\frac{f_{\mathrm{W}}\left(1+f_{\mathrm{R}}\right)}{f_{\mathrm{W}}+f_{\mathrm{R}}} z_{2}-b_{\mathrm{H}} \\
& a_{3,2}=-\frac{\mu_{\mathrm{H}}}{Y_{\mathrm{H}}} z_{1}+(1-f) b_{\mathrm{H}} \\
& a_{3,3}=-z_{2} \\
& a_{4,2}=\frac{Y_{\mathrm{H}}-1}{Y_{\mathrm{H}}} \mu_{\mathrm{H}} z_{1} \\
& a_{4,4}=-K z_{3}-z_{2} \\
& b_{1,4}=K_{1} \\
& b_{2,1}=b_{3,2}=z_{2} \\
& b_{4,3}=K \cdot S_{\mathrm{O}, \text { sat }}
\end{aligned}
$$

The system presents three nonlinearities. The premise variables are

$$
\left\{\begin{array}{l}
z_{1}\left(S_{\mathrm{S}}, S_{\mathrm{O}}\right)=\frac{S_{\mathrm{S}}}{K_{\mathrm{S}}+S_{\mathrm{S}}} \cdot \frac{S_{\mathrm{O}}}{K_{\mathrm{OH}}+S_{\mathrm{O}}} \\
z_{2}\left(q_{\mathrm{in}}, V\right)=\frac{q_{\text {in }}}{V} \\
z_{3}\left(q_{\mathrm{a}}\right)=q_{\mathrm{a}}
\end{array}\right.
$$

The idea of taking the premise variable $z_{1}$ as the product of the two Monod laws, without separating them, is to reduce in this way the premise variable number. The chosen premise variables are expressed respectively as the Monod law product $\left(z_{1}\right)$, the dilution rate $\left(z_{2}\right)$, and the air flow $\left(z_{3}\right)$. Concerning the physical meaning in the real process, the first premise variable $z_{1}$ represents the growth of the heterotrophic biomass $X_{\mathrm{BH}}$, the second one $\left(z_{2}\right)$ illustrates the dwell-time, and the third premise variable $z_{3}$ expresses the oxygenation level.
Table 5. Table of Maximum and Minimum Values

\begin{tabular}{lll}
\hline & $\min$ & $\max$ \\
\hline$V\left[\mathrm{~m}^{3}\right]$ & 1250 & 1337 \\
$S_{\mathrm{S}}\left[\mathrm{g} / \mathrm{m}^{3}\right]$ & 1.28 & 4.1 \\
$S_{\mathrm{O}}\left[\mathrm{g} / \mathrm{m}^{3}\right]$ & 0.92 & 6.88 \\
$q_{\text {in }}[\mathrm{M} 1 / 24 \mathrm{~h}]$ & 6.22 & 11.74 \\
$q_{\mathrm{a}}\left[\mathrm{M}^{3} / \mathrm{min}\right]$ & 1.155 & 8.25
\end{tabular}

Subsequently, by using the convex polytopic transformation, the three premise variables $z_{1}, z_{2}$, and $z_{3}$ are written like in eq 20 , where the two partitions of each premise variable are constructed in the same way as in eq 21 and with the scalars of eq 22. To calculate the maximum and the minimum values that occur in $z_{1}, z_{2}$, and $z_{3}$ expressions, we use the fact that $V, S_{\mathrm{S}}$, $S_{\mathrm{O}}, q_{\text {in }}$, and $q_{\mathrm{a}}$ are physically bounded (Table 5).

The number of submodels is $2^{3}=8$ and will be represented by the pairs $\left(A_{i}, B_{i}\right)(i=1, \ldots, 8)$ :

$$
\begin{array}{ll}
A_{1}=A\left(z_{1,1}, z_{2,1}, z_{3,1}\right) & B_{1}=B\left(z_{2,1}\right) \\
A_{2}=A\left(z_{1,1}, z_{2,1}, z_{3,2}\right) & B_{2}=B\left(z_{2,1}\right) \\
A_{3}=A\left(z_{1,1}, z_{2,2}, z_{3,1}\right) & B_{3}=B\left(z_{2,2}\right) \\
A_{4}=A\left(z_{1,1}, z_{2,2}, z_{3,2}\right) & B_{4}=B\left(z_{2,2}\right) \\
A_{5}=A\left(z_{1,2}, z_{2,1}, z_{3,1}\right) & B_{5}=B\left(z_{2,1}\right) \\
A_{6}=A\left(z_{1,2}, z_{2,1}, z_{3,2}\right) & B_{6}=B\left(z_{2,1}\right) \\
A_{7}=A\left(z_{1,2}, z_{2,2}, z_{3,1}\right) & B_{7}=B\left(z_{2,2}\right) \\
A_{8}=A\left(z_{1,2}, z_{2,2}, z_{3,2}\right) & B_{8}=B\left(z_{2,2}\right)
\end{array}
$$

To be clear with these notations, let us recall for example, that $A_{1}$ is obtained using definition 34 , where $a_{2,2}, a_{3,2}, a_{3,3}, a_{4,2}, a_{4,4}$ are computed by using the minimal value of $z_{1}, z_{2}, z_{3}$ (eq 35).

The multiple model is obtained by an interpolation of the eight previous submodels:

$$
\dot{x}=\sum_{i=1}^{8} \mu_{i}(x, u)\left(A_{i} x+B_{i} u\right)
$$

The weighting functions $\mu_{i}(x, u)(i=1, \ldots, 8)$ are calculated in the same way as in eq 23 , in conformity with definition 35 .

For example, we have

$$
\begin{aligned}
& \mu_{1}(x, u)=F_{1,1}\left(S_{\mathrm{S}}, S_{\mathrm{O}}\right) F_{2,1}\left(V, q_{\mathrm{in}}\right) F_{3,1}\left(q_{\mathrm{a}}\right)= \\
& \frac{\frac{S_{\mathrm{S}}}{K_{\mathrm{S}}+S_{\mathrm{S}}} \frac{S_{\mathrm{O}}}{K_{\mathrm{OH}}+S_{\mathrm{O}}}-0.06}{0.16-0.06} \cdot \frac{\frac{q_{\text {in }}}{V}-0.48}{0.92-0.48} \cdot \frac{q_{\mathrm{a}}-1.155}{8.25-1.155}
\end{aligned}
$$

In Figure 3 we can see the evolution of the system eq 33 which has been obtained by using formulation 36 obtained for: $K_{\mathrm{S}}=20 \mathrm{~g} / \mathrm{m}^{3}, K_{\mathrm{OH}}=0.2 \mathrm{~g} / \mathrm{m}^{3}, S_{\text {O,sat }}=10 \mathrm{~g} / \mathrm{m}^{3}, K=2.3 \mathrm{~m}^{-3}$, $K_{1}=0.01, b_{\mathrm{H}}=0.4(1 / 24) \mathrm{h}^{-1}, \mu_{\mathrm{H}}=3.733(1 / 24) \mathrm{h}^{-1}, Y_{\mathrm{H}}=$ $0.6, f=0.1, f_{\mathrm{R}}=1.1, f_{\mathrm{W}}=0.03$, with the initial conditions:

$$
x(0)=\left[\begin{array}{l}
V(0) \\
X_{\mathrm{BH}}(0) \\
S_{\mathrm{S}}(0) \\
S_{\mathrm{O}}(0)
\end{array}\right]=\left[\begin{array}{l}
1250 \mathrm{~m}^{3} \\
887 \mathrm{~g} / \mathrm{m}^{3} \\
4.2 \mathrm{~g} / \mathrm{m}^{3} \\
3 \mathrm{~g} / \mathrm{m}^{3}
\end{array}\right]
$$


and under the inputs presented in Figure 2.

The $q_{\text {in }}$ input flow influences the three concentrations $X_{\mathrm{BH}}$, $S_{\mathrm{S}}$, and $S_{\mathrm{O}}$. An increase of the input flow $\left(q_{\mathrm{in}}\right)$ produces an increase of the substrate concentration $\left(S_{\mathrm{S}}\right)$ and the heterotrophic biomass concentration $\left(X_{\mathrm{BH}}\right)$, as well as a decrease of the dissolved oxygen concentration $\left(S_{\mathrm{O}}\right)$. At the same time, $S_{\mathrm{O}}$ is directly influenced by the air flow $\left(q_{\mathrm{a}}\right), X_{\mathrm{BH}}$, and $S_{\mathrm{S}}$ inside the reactor being influenced by the corresponding input reactor concentrations $\left(X_{\mathrm{BH} \text {,in }}\right.$ and $\left.S_{\mathrm{S} \text {,in }}\right)$. The range of speed response of the dissolved oxygen, soluble carbon, and heterotrophic biomass is obvious.

For space and clarity reasons, not all of the eight weighting functions of the multiple model 36 are presented in Figure 4 but only four of them. It has to be remarked that $q_{\mathrm{in}}, q_{\mathrm{a}}, V_{\text {ref }}$, $X_{\mathrm{BH} \text {,in }}$ and $S_{\mathrm{S} \text {,in }}$ also have an influence on the weighting functions of the multiple model. For example, the seventh submodel is active if a good oxygenation is ensured (high level of the air flow $q_{\mathrm{a}}$ ), if there is no important growth of the soluble components and if the dwell-time (corresponding to important dilution rate $z_{2}$ ) is weak (see the periods of time $t=2.3-3.5 \mathrm{~h}$ and $t=5.5-6.5 \mathrm{~h}$ ). For a high dwell-time, the fifth submodel plays an important role (see the periods of time $t=3.5-3.8 \mathrm{~h}$ and $t=6.5-6.7 \mathrm{~h})$. A weak oxygenation $(1.7-2.3 \mathrm{~h}$ and $6.7-9$

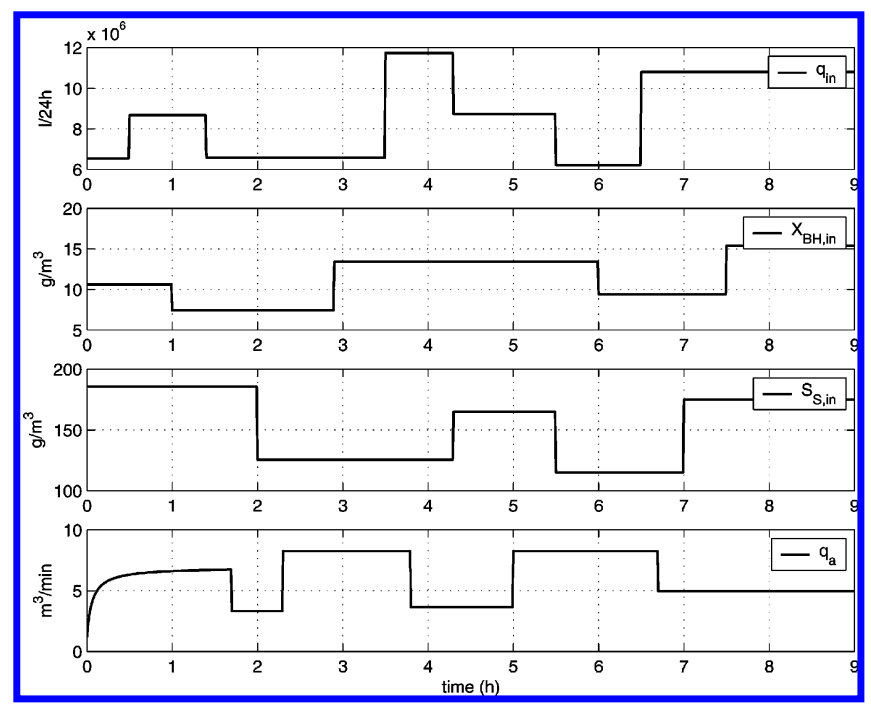

Figure 2. Inputs of the system.

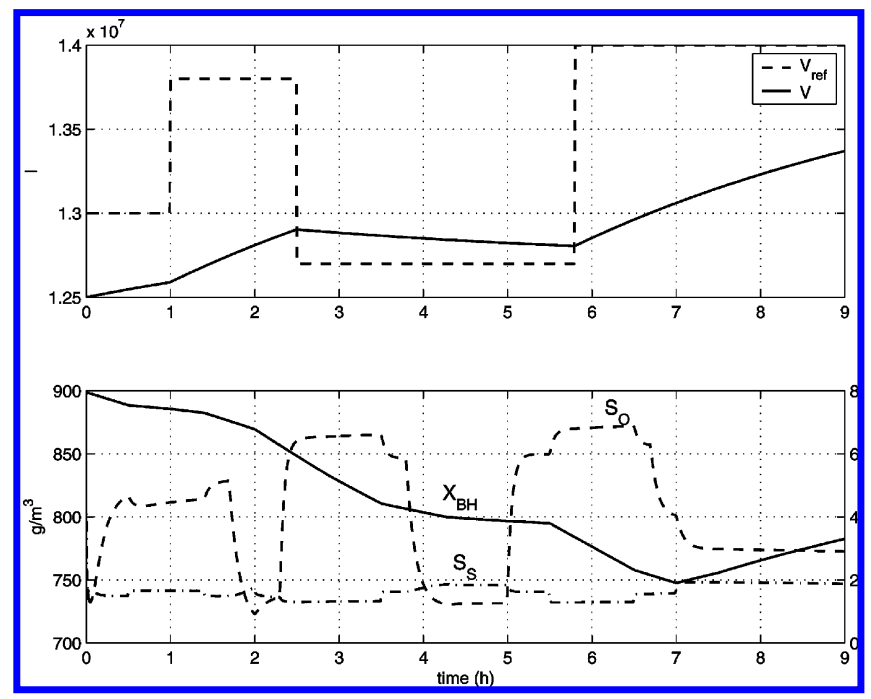

Figure 3. Evolution of system 33 under the inputs from Figure 2.

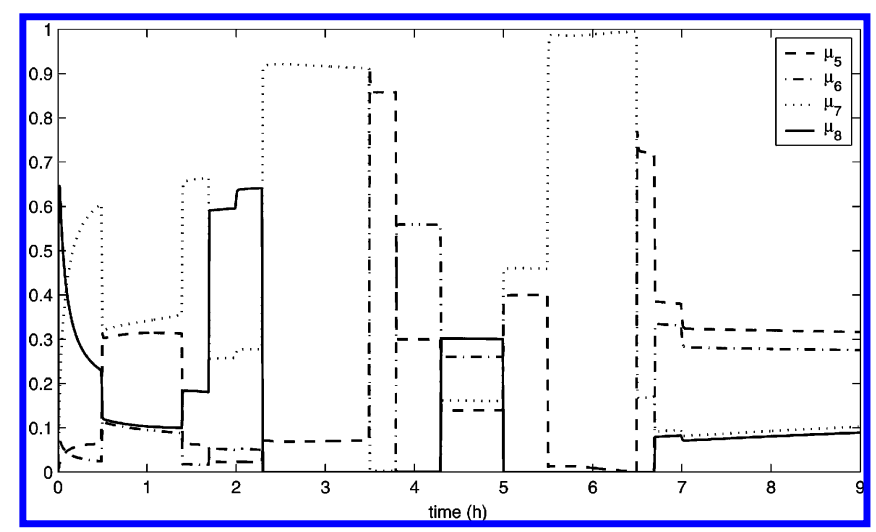

Figure 4. Some weighting functions of the associated multiple model.

h), a weak growth of the soluble components, and weak dwelltime $(2-2.3 \mathrm{~h})$ activate the eighth submodel, and so on.

\section{Conclusion}

This article proposes a general analytical method to simplify the complexity of a nonlinear system by rewriting it into a multiple model. This substitution consists in finding a set of submodels with a simple linear structure and a set of appropriated weighting functions in order to combine these submodels to constitute the global model.

To obtain a multiple model this article proposes a general method to rewrite the nonlinear model into a multiple model form avoiding the need to choose the operating points or trajectories. Additionally, systematic rules are proposed to choose the premise variables.

From the expression of a nonlinear system, we showed how to realize a systematic decomposition of a system into simpler linear systems by constructing a multiple model. It is important to note that the obtained multiple model is identical to the initial system. This decomposition method can be applied to any order systems. Another important aspect concerning this decomposition method is the given possibility to choose between several quasi-LPV forms of the nonlinear system that lead to specific properties of the multiple model structure. Such properties may be controller or observer design for multiple model structures with regard to the study objectives. This method also gives the possibility to reduce the number of submodels by an adequate choice of premise variables between several sets of candidate premise variables.

From a practical point of view, this method is applied to a simplified activated sludge reactor model and leads to a multiple model structure based on eight local models. Even if in this article we have treated the case of a simplified ASM1 model, considering only the carbon pollution, the proposed method can be applied to the whole ASM1 model, as the difficulties are similar (nonlinearities expressed by the Monod law, the dilution rate, and air flow).

\section{Acknowledgment}

We acknowledge the financial support received from the "Fonds National de la Recherche Luxembourg". This research is also partially supported by the PHC TASSILI no.07 program under MDU Grant 714.

\section{Literature Cited}

(1) Dolgin, Y.; Zeheb, E. Model reduction of uncertain systems retaining the uncertainty structure. Syst. Control Lett. 2005, 54, 771-779. 
(2) Hetherington, J.; Warner, A.; Seymour, R. Simplification and its consequences in biological modelling: Conclusions from a study of calcium oscillations in hepatocytes. J. R. Soc. Interface 2006, 3, 319-331.

(3) Petzold, L.; Zhu, W. Model reduction for chemical kinetics: An optimization approach. AIChE J. 1999, 45, 869-886; No. 4.

(4) Moore, B. Principal component analysis in linear systems: Controllability, observability and model reduction. IEEE Trans. Automat. Control 1981, 26, 17-32.

(5) Sayesel, A. K.; Barlas, Y. Model simplification and validation with indirect structure validity tests. Syst. Dyn. Rev. 2006, 22, 241-262.

(6) Andersson, L.; Rantzer, A.; Beck, C. Model comparison and simplification. Int. J. Robust Nonlinear Control 1996, 9, 157-181.

(7) Steffens, M.; Lant, P.; Newell, R. A systematic approach for reducing complex biological wastewater treatement models. Water Res. 1997, 31, 590-606.

(8) Murray-Smith, R.; Johansen, T. Multiple Model Approaches to Modeling and Control; Taylor \& Francis: London, 1997.

(9) Mourot, G.; Gasso, K.; Ragot, J. Modelling of ozone concentrations using a Takagi-Sugeno model. Control Eng. Pract. 1999, 7, 707-715.

(10) Takagi, T.; Sugeno, M. Fuzzy identification of systems and its application to modelling and control. IEEE Trans. Syst., Man Cybernet 1985 15, 166-172.

(11) Angelis, G. Z. System Analysis, Modeling and Control with Polytopic Linear Models; Technische Universiteit Eindhoven: Eindhoven, The Netherlands, 2001.

(12) Johansen, T.; Shorten, R.; Murray-Smith, R. On the interpretation and identification of dynamic Takagi-Sugeno fuzzy models. IEEE Trans. Fuzzy Syst. 2000, 8, 297-313.

(13) Abonyi, J.; Babuska, R.; Szeifert, F. Modified Gath-Geva fuzzy clustering for identification of Takagi-Sugeno fuzzy models. IEEE Trans. Syst., Man, Cybernet., Part B 2002, 32, 612-621.

(14) Akhenak, A.; Chadli, M.; Ragot, J.; Maquin, D. Estimation of state and unknown inputs of a nonlinear system represented by a multiple model. 11th IFAC Symposium on Automation in Mining, Mineral and Metal processing, MMM, Nancy, France, 2004.

(15) Chadli, M.; Maquin, D.; Ragot, J. On the stability analysis of multiple model systems. European Conference Control (ECC), Porto, Portugal, 2001.
(16) Tanaka, K.; Wang, H. Fuzzy Control System Design and analysis. A Linear Matrix Inequality Approach; John Wiley \& Sons Inc.: New York, 2001

(17) Olsson, G.; Newell, B. Wastewater Treatment Systems. Modelling, Diagnosis and Control; IWA Publishing, London, 1999.

(18) Smets, I.; Verdickt, L.; Van Impe, J. A linear ASM1 based multimodel for activated sludge systems. Math. Comput. Model. Dyn. Syst. 2006, 12, 489-503.

(19) Wang, H. O.; Tanaka, K.; Griffin, M. An approach to fuzzy control of nonlinear systems: Stability and design issues. IEEE Trans. Fuzzy Syst. 1996, 4, 14-23.

(20) Ohtake, H.; Tanaka, K.; Wang, H. Fuzzy modeling via sector nonlinearity concept. Joint 9th IFSA World Congress and 20th NAFIPS International Conference, Vancouver, Canada, July 25-28, 2001.

(21) Ichalal, D.; Marx, B.; Ragot, J.; Maquin, D. State estimation of nonlinear systems using multiple model approach. American Control Conference, ACC, St. Louis, Missouri, USA, 2009, accepted.

(22) Huang, Y.; Jadbabaie, A. Nonlinear Hinf Control: An enhanced Quasi-LPV Approach. IFAC World Congr. 1999, 85-90.

(23) Guerra, T.; Kruszewski, A.; Bernal, M. Control law proposition for the stabilization of discrete Takagi-Sugeno models. IEEE Trans. Fuzzy Syst. 2009, 17, 724-731.

(24) Tanaka, K.; Ohtake, H.; Wang, H. O. A descriptor system approach to fuzzy control system design via fuzzy Lyapunov functions. IEEE Trans. Fuzzy Systems 2007, 15, 333-341.

(25) Bergsten, P.; Palm, R. Thau-Luenberger observers for TS fuzzy systems. The 9th IEEE Int. Conf. Fuzzy Systems, San Antonio, Texas, 2000.

(26) Bergsten, P.; Palm, R.; Driankov, D. Fuzzy Observers. Fuzzy Observ. 2001, 700-703.

(27) Ichalal, D.; Marx, B.; Ragot, J.; Maquin, D. Simultaneous state and unknown inputs estimation with PI and PMI observers for TakagiSugeno model with unmeasurable premise variables. 17th Mediterr. Conf. Control Automat. (MED '09) 2009, 353-358.

(28) Murphey, T.; Burdick, J. Nonsmooth controllability theory and an example. Proc. 41st IEEE Conf. Decis. Control 2002, 370-376. 